\title{
Working and Learning during the COVID-19 Confinement: An Exploratory Analysis with a Small Sample from Portugal
}

\author{
Alexandra Dias Martins and Sónia Rolland Sobral *ii \\ Departamento de Ciência e Tecnologia, Universidade Portucalense, 4200 Porto, Portugal; 40601@alunos.upt.pt \\ * Correspondence: sonia@upt.pt
}

Citation: Martins, A.D.; Sobral, S.R. Working and Learning during the COVID-19 Confinement: An

Exploratory Analysis with a Small Sample from Portugal. Informatics 2021, 8, 44. https://doi.org/10.3390/ informatics 8030044

Academic Editors: Guendalina Capece and Flavia Di Costa

Received: 31 May 2021

Accepted: 28 June 2021

Published: 30 June 2021

Publisher's Note: MDPI stays neutral with regard to jurisdictional claims in published maps and institutional affiliations.

Copyright: (c) 2021 by the authors. Licensee MDPI, Basel, Switzerland. This article is an open access article distributed under the terms and conditions of the Creative Commons Attribution (CC BY) license (https:// creativecommons.org/licenses/by/ $4.0 /)$.

\begin{abstract}
The epidemiological situation caused by the COVID-19 pandemic led to efforts to mitigate the transmission of the infection, forcing workers and students to stay at home. Universities closed, as did many businesses, forcing education and work to adapt to the new situation. While for some people it was a positive experience, for others it was not. This article analyzes the responses of 89 respondents, over 18 years old, in teleworking or enrolled in university online education, in a survey at the beginning of 2021, when Portugal was in a new state of emergency. Variables such as gender, age and parenthood were used, as well as ownership of equipment, own workspace, and quality of internet, comparing distance learning/work with traditional methods and measuring levels of satisfaction and willingness to adopt this model in the future. These results suggest an association of gender and parenting in the valuation of telework/distance education; women were more positive than men and participants with children were more positive than participants without children. The same was the case for respondents with their own workspace and better-quality internet. There is a strong relation between paternity and the preference for the distance model, in the sense of valuing the distance model, as well as a relation between those who have their own work space and the appreciation of the distance model. In general, respondents to our survey showed that they are not fond of adopting telework/distance learning in the future.
\end{abstract}

Keywords: COVID-19; teleworking; e-learning; parenthood; work facilities

\section{Introduction \\ 1.1. COVID-19 Pandemic}

On 11 March 2020, the Director-General of the World Health Organization classified COVID-19 as a pandemic [1]. Companies around the world had to quickly adapt to teleworking and reinvent themselves [2,3]. Higher education institutions had to find solutions for emergency remote education $[4,5]$. Work and study that were normally done at the company or the educational institution began to be mandatorily done from home.

The President of the Portuguese Republic first decreed a state of emergency to be effective from 19 March 2020 [6], with successive renewals until 2 May at 11:59 pm. Starting from 16 March 2020, the government decided "to suspend teaching and training activities with the presence of students" [7]. On 22 March 2020, several measures introduced by the Presidency of the Council of Ministers came into effect [8], including the mandatory "adoption of the teleworking regime, regardless of the employment relationship, whenever the functions in question allow it". For more than a year, there has been progress and setbacks in some of these measures. The worsening of the health situation forced the Presidency of the Republic to declare a new state of emergency [9], going into effect 8 January 2021 until 11:59 pm on 30 April 2021.

\subsection{Higher Education}

Higher education institutions had to adapt quickly and find solutions for emergency distance learning. Distance learning, especially b-learning or blended learning, is present 
in most Portuguese institutions. Distance education is characterized as a planned teaching in which there is physical and/or temporal distance from the different interveners in the process, using synchronous and/or asynchronous solutions [10]. Emergency distance learning differs from the traditional method, because it is not a previously planned activity. Instead, emergency distance learning is a solution to help individuals overcome the problems created by students and teachers being physically close.

\subsection{Telework}

Teleworking has not been traditionally used in Portugal; in 2019 [11], only 6.5\% of workers were working from home, despite the percentage of private homes with broadband Internet connection being $81.7 \%$ in 2020 [12]. Teleworking is defined by Portuguese legislation as "the provision of subordinate work, usually outside the company and using information and communication technologies, when it is compatible with the activity performed" [13]. However, this presupposes that there is a working schedule that respects a worker's privacy and rest times as well as training in information technologies. Furthermore, the work tools related to information and communication technologies that are used by the worker belong to the employer, who must ensure the respective installation, maintenance, and payment of the related expenses. In other words, an entire area of legislation could not be addressed due the urgency of the process. Therefore, emergency remote work differs in several aspects from teleworking, essentially because it is compulsive and it is not an agreement between the company and the worker.

\subsection{Effects of COVID-19 Outbreak}

The effects of COVID-19 are impossible to predict, not only because of the terrible number of deaths and the economic consequences, but also the related mental health problems. Castelli et al. describe that $69 \%$ of study participants revealed clinically relevant anxiety, $31 \%$ showed depressive symptoms, and 20\% exhibited significant Post-Traumatic Stress Symptoms, facing the COVID-19 outbreak as a psychological trauma [14]. GutiérrezHernández et al. estimate that about $30 \%$ of individuals have clinically significant levels of anxiety, depression, and stress, and the variables most frequently associated were low levels of self-pity, age, gender, previous physical symptoms, a previous mental disorder, being a student, and having a perceived vulnerability to the disease [15]. A systematic review of the psychological effects of social distancing due to the home confinement derived from COVID-19 showed that women, young people, the unemployed, and patients with prior mental or psychiatric illnesses were the most vulnerable [16]. Likewise, it was found that those who had suspected COVID-19 symptoms were more likely to have depression and low health-related quality of life [17]. A UK study found symptoms of anxiety or depression and trauma were predicted by early age, presence of children at home, and high estimates of personal risk; higher levels of anxiety and depression were predicted by low income, loss of income, and pre-existing health conditions in self and others, with anxiety levels specific to COVID-19 being higher in older participants [18]. A survey of psychological distress among Italian people during the COVID-19 pandemic concluded that female gender, negative affect, and detachment were associated with higher levels of depression, anxiety, and stress; having an acquaintance infected was associated with increased levels of both depression and stress, whereas a history of stressful situations and medical problems was associated with higher levels of depression and anxiety. Having a family member infected was associated with higher levels of anxiety, and families with a young person who had to work outside the domicile were associated with higher stress [19]. Based on an online survey, divided into five age groups and sociodemographic, health, and behavioral variables, mental health assessed by the Depression, Anxiety and Stress Scale (DASS-21) and psychological impacts assessed by the Assessment of Impact Scale Events (IES-R) showed evidence that the negative psychological impact of the COVID-19 pandemic hits young people most strongly [20]. More than a quarter of Swiss university students reported depressive symptoms, a significantly higher percentage than the corresponding 
general population. In a study focused on university students in Poland, four demographic variables were possibly associated with General Health Questionnaire scores: female gender, living in a big city, the need to return home, and having a relationship [21]. At a Spanish university, $50.43 \%$ of respondents had moderate to severe impacts, with moderate to extremely severe scores of anxiety, depression, and stress reported by $21.34 \%, 34.19 \%$ and $28.14 \%$ of respondents, respectively [22]. In a study at an American university, $48.14 \%$ of respondents had a moderate to severe level of depression, $38.48 \%$ a moderate to severe level of anxiety, $18.04 \%$ had suicidal thoughts, and $71.26 \%$ indicated that their stress and anxiety levels increased during the pandemic [23]. From what has been exposed in this section, there are studies that point to the prevalence of symptoms in a certain age or group, but the problem of anxiety, depression, and stress reveals itself in all sectors of society.

\subsection{Working and Learning at Home during the Pandemic}

The pandemic forced a transition from teaching and work from its normal place to the homes of different stakeholders in the process, in an unplanned and involuntary manner. We found that studies have different focuses, such as working at home and dietary changes during the COVID-19 pandemic [24]. A Norwegian study investigated the association between external and internal digital knowledge and employees' creative performance, using demographic, individual, and organizational factors [25]. Based on an online survey distributed in six police districts in Norway, it was shown that extroversion was not related to satisfaction with the arrangement of the home office when controlling for other relevant variables (like stress, only a home office, living alone, age, sex, and civil employment). A higher score on extroversion was associated with missing colleagues; a marginal negative association, although significant, was found between extroversion and stress, and a positive relationship was found between stress and missing peers during confinement, regardless of extroversion [26]. A study of workers who suffered from body aches in the four weeks prior to the study showed $15 \%$ of participants reported that the pain worsened during the COVID-19 pandemic and 47\% reported decreased physical activity and increased psychological stress [27]. A study that included workers in the Australian construction industry indicated a consistent gradual decline in participants' mental well-being as well as a positive and significant relationship between work life satisfaction and mental well-being [28]. A study that investigated the impact of mandatory work on the personal and professional lives of people with different demographics (gender, healthy lifestyle, family bond, and physical stress, among others) positively associated the impact on emotional well-being with gender, groups, industry, and family size [29]. From what has been exposed in this section, there are several studies on working and studying from home; however, it does not seem that there is a very strong approach to studying particular demographic groups or certain characteristics.

\subsection{This Study}

The question arises: What was the perception of these stakeholders in relation to the "new normal"? Several studies have been carried out in different countries to understand the sensations and productivity of workers at home. We found several publications from different countries, for example, Ecuador [30], Lithuania [31], Brazil [32], France [3], Austria [33], Vietnam [34], Japan [35], United States [36], Italy [37], and Latvia [38]. However, with a search using telework as the keyword in databases such as SCOPUS and Web of Science, we did not find any results from the pandemic years of 2020 and 2021 in Portugal. We know that some countries share factors in common with Portugal, but we also know that teleworking has different percentages of supporters/users (in pre-COVID-19 times), depending on the country. If we look at the percentages of people working from home in 2019, we find that in Bulgaria and Romania it was less than 1\%, Portugal 6.5\%, and $14.1 \%$ in Finland and the Netherlands. This research project analyzes teleworking and elearning, with a focus on people's experience, since many scientific works direct their focus to health workers [39,40] or to a particular group [41]. This study analyzes the responses 
of 89 respondents, over 18 years old, in teleworking or in university online education, in a survey at the beginning of 2021, when Portugal was in a new state of emergency. Our analysis was based on the assumption that there are no demographic groups, or groups with certain characteristics, that are more likely to like, prefer, or want to adopt the distance model compared to the traditional face-to-face model. The results are not very encouraging for great proponents of the advantages of teleworking [42-44] those who think that the future should move towards a model of teaching and working at a distance or a hybrid model [45], at least in Portugal and according to our sample.

This article is divided into research issues/methodology, results, discussion, and conclusions.

\section{Research Issues and Methodology}

\subsection{Research Questions}

To achieve the objectives under reflection, this investigation intends to answer the following questions:

H1: Is there a correlation between demographic groups (gender, age group, parenthood) and the perception of telework/distance education by the individuals who use it?

H2: Do the environment variables (hardware, individual or shared physical space, internet quality) in which telework/distance education is practiced have an impact on its perception?

H3: Would people be willing or not to adopt telework/distance education?

Regarding these questions, we believe it is important to highlight the interconnection between the first two issues. This is because both focus on the assessment of the perception of the alternative (e-learning/teleworking) by individuals, differing only in the variables (the first focusing on demographic variables intrinsic to the individual and the second on variables related to the surrounding environment). With these questions, we intend to perform an analysis that is independent of the pre-pandemic reality. In contrast, the third question inserts the alternative in a comparative space, in which one analyzes its viability in the future (e.g., an individual may have a positive experience, but still prefer the so-called normal regime). Thus, for the investigation, the ideal recipients are professionals who have adopted the teleworking regime and university students.

This study will be analyzed based on the assumption that there are no demographic groups or groups with certain characteristics that are more likely to like, prefer, or want to adopt the distance model compared to the traditional face-to-face model.

\subsection{Participants}

This investigation was carried out according to a quantitative methodological approach, in which the aim was to mirror, in numerical expressions, the opinions and information to be classified and analyzed. To ascertain the presence of links between the independent variables and the participants' opinions, this study relied on a correlational perspective, with the purpose of determining the existence, or not, of a relationship between quantifiable variables.

We attempted to answer the research questions by surveying students and workers over 18. The collection and compilation of data enabled an analysis, where the intention was to understand the perception of most people about the alternatives.

\subsection{Materials and Measures}

The instrument for surveying and collecting data was made available in electronic format. In accordance with the main objectives defined, a set of questions was organized into three different groups. The first referred to personal data and aimed to obtain sociodemographic information about the participants. The second group of questions was directed at the work/study environment of the individuals when using the alternatives. Finally, in the third group, the questions focused on the experience that the participants had when using the alternatives. The introductory part of the questionnaire presented the scope and 
purpose of the research study as well as guaranteeing the anonymity and confidentiality of the data to be collected. The interpretation of data from the second question of the second group was made according to the following response intervals in a Likert-type scale: $1=$ very poor; $2=$ bad; $3=$ neutral; $4=$ good; $5=$ very good. Regarding the first and last question of the third group, it is asked as follows: $1=\mathrm{I}$ do not like at all; $2=\mathrm{I}$ do not like it; $3=$ neutral; $4=$ like; $5=$ I like it a lot. We used the $p$-value, or probability value, which is a number that describes the probability that the null hypothesis is true, that is, the data occurred randomly. The $p$-value is between 0 and 1 ; the smaller it is, the stronger the evidence that the null hypothesis should be rejected.

\subsection{Procedure}

To prepare and make the questionnaire available, Google Forms was used. The inquiry was opened in the last two weeks of February 2021. The following figure (Figure 1) shows the monthly data of COVID-19 cases and deaths in Portugal from March 2020 to March 2021 [46,47]. We can see a first wave in April 2020, another in November 2020, and a third much more serious wave in January and February 2021.

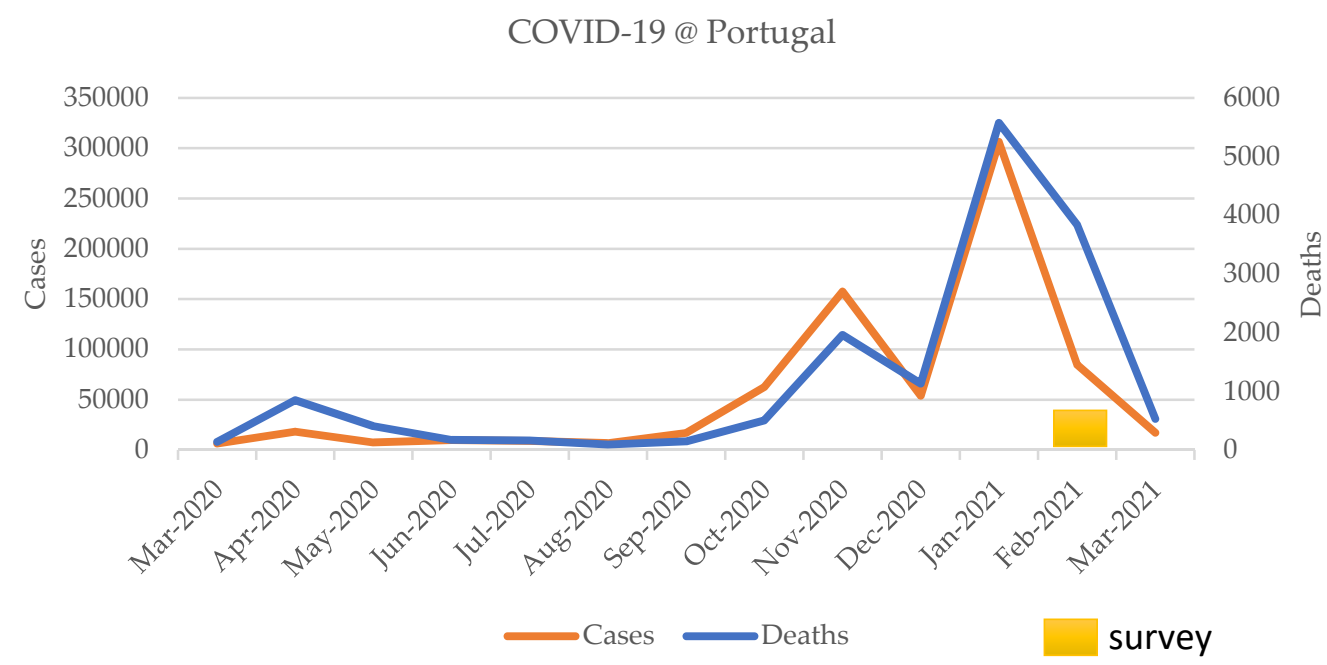

Figure 1. COVID-19 cases and deaths in Portugal during the survey timeframe.

The research contains three different moments of data collection and analysis: (a) first, gathering answers about the environment in which the subject was involved, (b) second, gathering answers about the experience of each of the subjects, and (c) third, comparison between the data, that is, between the environments and the perceptions of the alternatives, alongside an analysis of certain sociodemographic characteristics of the subjects. The data obtained from the application of the questionnaire was analyzed to characterize the participants and obtain the necessary information.

\section{Results}

The participants in the research study presented were professionals who adopted the teleworking regime and university students. A total of 92 individuals participated in the study, from which only 89 valid responses were obtained (willing to answer the survey and who had experienced teleworking or distance education).

\subsection{Demographics}

Of the 89 participants, 68 were female $(76.4 \%)$ and 21 male. Participants were between 18 and 51 years old, with 59 between 18 and 25 (66.29\%). Another important aspect regarding the participants of this study concerns parenthood, that is, whether they had children or not. Of the 89 , only 22 were parents $(24.7 \%)$, as we can see in Table 1. 
Table 1. Survey answers and $p$-value $(N=89)$.

\begin{tabular}{|c|c|c|c|c|c|c|c|c|}
\hline Gender & $N$ & $\%$ & Age & $N$ & $\%$ & Children & $N$ & $\%$ \\
\hline Male & 21 & $23.60 \%$ & $18-25$ & 59 & $66.30 \%$ & Yes & 22 & $24.70 \%$ \\
\hline Female & 68 & $76.40 \%$ & $26-35$ & 8 & $9.00 \%$ & No & 67 & $75.30 \%$ \\
\hline Other & 0 & $0.00 \%$ & $36-45$ & 10 & $11.20 \%$ & & & \\
\hline & & & $46+$ & 12 & $13.50 \%$ & & & \\
\hline $\begin{array}{c}\text { Own } \\
\text { Equipment }\end{array}$ & $N$ & $\%$ & $\begin{array}{l}\text { Internet } \\
\text { Quality }\end{array}$ & $N$ & $\%$ & $\begin{array}{l}\text { Own } \\
\text { Space }\end{array}$ & $N$ & $\%$ \\
\hline Yes & 86 & $96.63 \%$ & 1 & 0 & $0.00 \%$ & Yes & 69 & $77.53 \%$ \\
\hline No & 3 & $3.37 \%$ & 2 & 3 & $3.37 \%$ & Sometimes & 7 & $7.87 \%$ \\
\hline & & & 3 & 15 & $16.85 \%$ & No & 13 & $14.61 \%$ \\
\hline & & & 4 & 45 & $50.56 \%$ & & & \\
\hline & & & 5 & 26 & $29.21 \%$ & & & \\
\hline \multicolumn{3}{|c|}{ Teleworking-e-learning } & \multicolumn{3}{|c|}{ Distance vs. Face-to-Face } & \multicolumn{3}{|c|}{ Future implementation } \\
\hline & $N$ & $\%$ & & $N$ & $\%$ & & $N$ & $\%$ \\
\hline 1 & 11 & $12.36 \%$ & 1 & 7 & $7.90 \%$ & 1 & 34 & $38.20 \%$ \\
\hline 2 & 18 & $20.22 \%$ & 2 & 32 & $36.00 \%$ & 2 & 13 & $14.60 \%$ \\
\hline 3 & 37 & $41.57 \%$ & 3 & 20 & $22.50 \%$ & 3 & 20 & $22.50 \%$ \\
\hline 4 & 22 & $24.72 \%$ & 4 & 21 & $23.60 \%$ & 4 & 19 & $21.30 \%$ \\
\hline 5 & 1 & $1.12 \%$ & 5 & 9 & $10.10 \%$ & 5 & 3 & $3.40 \%$ \\
\hline Gender & & 0.0123 & & & 0.9611 & & & 0.7365 \\
\hline Age & & 0.4653 & & & 0.1519 & & & 0.3069 \\
\hline Parenthood & & 0.0113 & & & 0.0001 & & & 0.1793 \\
\hline Own Equipment & & 0.6952 & & & 0.6865 & & & 0.2850 \\
\hline Internet Quality & & 0.0384 & & & 0.0912 & & & 0.1948 \\
\hline Own Space & & 0.0126 & & & 0.0175 & & & 0.0603 \\
\hline
\end{tabular}

\subsection{Work/Study Environment}

Of the responses given by the participants regarding their work/study environment, only $3.4 \%$ of the total respondents did not have their own equipment with an internet connection for their exclusive use, and no one answered that the quality of the internet was very poor. In addition, $77.5 \%$ of respondents answered that they always have a space where they can work/attend classes online/study alone, as we can see in Table 1.

\subsection{Perception about Teleworking/Distance Learning}

In the analysis of the respondents' perception of telework/distance learning, it was possible to conclude that the appreciation for these alternatives is neutral, with $41.6 \%$ of the participants answering level 3 (scale $1-5$ ). Only $1.1 \%$ of responses indicated liking it a lot. That is, in general, the participants neither liked nor disliked it. Regarding learning, we found the highest percentage of responses in level 2, that is, respondents work/learn less when using the alternatives, as is shown in Table 1. Regarding the desire for future implementation, 3.4\% of the participants answered level 5 (I liked it a lot) and 38.2\% level 1 (I did not like it at all). Thus, in general, individuals learn less and have no desire to implement alternatives in the future.

\subsection{Overall Results}

In Table A1, we list the absolute and relative variables obtained by the questionnaire, as well as the $p$-value associated with each demographic variable (gender, age, and parenthood) and work constraints (own equipment, own space, and internet quality) at the level of appreciation of the distance learning model, preference of the distance model in comparison to the face-to-face model and adopting the remote model in the future.

\section{Discussion}

\subsection{First Research Question}

The first question of this investigation is as follows: Is there a correlation between demographic groups (gender, age group, parenthood) and the perception of telework/distance education by the individuals who use it? Regarding appreciating telework/distance learning by gender, both female and male respondents fit with the general average of responses, 
which is 2.82. However, we can see that the male gender is closer to the dislike response (2.48), while the female gender is closer to the neutral response (2.93). By age group, in relation to those aged $36-45$ and $46+$, the average response points to a neutral opinion, while the rest were found at level 2 . In terms of parenthood, there is a difference in response between participants with children and those without children. Participants with children had an average of 3.14, that is, a neutral opinion, and participants without children had an average of 2.72 , that is, they did not like the alternatives. We assumed from the beginning that each of the groups had as much probability as the other; the $\mathrm{p}$ values for gender, age, and parenthood are, respectively, $0.0123,0.4653$, and 0.0113 . These numbers suggest that there is no association for age, but there is for gender and parenthood.

Comparing distance working/learning with face-to-face by gender, there was no fluctuation in responses. Both the female and male genders had an average response that matched the general average (2.92); therefore, we conclude that for both genders the opinion is that they worked/learned less. By age group, the highest average level of response was the 36-45-year-old age group, which was the closest to a positive response (3.90). By parenthood, there were significant differences between participants with children (3.64) and those without children (2.69), which means that the former believe they are working/studying more than in person. The $p$-values $(0.9610,0.1519$, and 0.0001$)$ suggest that there is a strong association between parenthood and preference of the distance model.

Regarding the desire for the future implementation of the alternatives, we did not see any differences in the average of the responses by gender, by age group, or by parenthood, ( $p$-values, respectively, of $0.7365,0.3069$, and 0.1793 ).

\subsection{Second Research Question}

The second question of this investigation is as follows: Do the environment variables (own hardware, individual or shared physical space, internet quality) in which telework/distance education is practiced have an impact on its perception? Regarding the appreciation of telework/distance education, the average of the responses of individuals with their own personal equipment is close to level 3 (neutral), whereas those who did not have it were exactly at level 2; that is, the latter did not like it. Regarding the quality of the internet connection, individuals with poor internet connection (2) had less appreciation for the alternatives (1.67), and those who had very good connection had an average response of 3. Regarding the perception of respondents considering the work/study space, it is possible to confirm that significant oscillation occurred in individuals who had their own space; however, it was higher in those who only sometimes had their own space (3.29). The $p$-values of $0.6952,0.0383$, and 0.0126 suggest an association with respondents who have their own work space and that they appreciate the distance model, as well as an association with the variable of internet quality.

Analyzing the comparison of distance with face-to-face work/learning, considering the existence or not of one's own equipment, it is verified that the participants with their own equipment had an average of responses very close to neutral, unlike those who shared equipment, where the average that was worked/learned was less. Analyzing the responses obtained in relation to the quality of the internet connection, crossing with the perception of individuals, the respondents who had very good internet quality had the highest average (3.23), while those who had poor internet quality had the lowest average (2.67). Regarding the perception of respondents considering the work/study space, we see that people without their own space answered that they worked/learned less (2.83). The $p$-values $(0.6864,0.0912$, and 0.0175$)$ tell us that there is an association between having one's own workspace and preferring the distance model to the face-to-face one.

Finally, in relation to the desire for future implementation of remote alternatives, on average, people with personal equipment had a greater desire (2.42), even though slight, than people who shared equipment. It was also seen that the desire of individuals with poor internet connection was, on average, very little (1) and that it was the respondents who partially have their own space to work/study who wanted, on average, the distance 
model the most. The $p$-values of $0.2850,0.1948$, and 0.0602 do not suggest any strong association, although the $p$-value for parenthood was close to 0.05 .

\subsection{Third Research Question}

The third question of this investigation is as follows: Would people be willing or not to adopt telework/distance education?

It is possible to see that only $3.37 \%$ of the respondents really liked the possibility of alternatives being implemented in the future and that $38.2 \%$ did not really like it at all. Considering the scale of 1 to 5 , there was an average response of 2.37, pointing to a negative general opinion. Furthermore, the mode of the data sample was level 1 (the worst), which was the most frequent answer. We can conclude that people in general are not willing to adopt telework/distance education.

\section{Conclusions}

With this investigation it was possible to meet the objectives of knowing the experiences perceived by several individuals in Portugal in teleworking and in distance learning, both mandatory due to the serious pandemic situation, the conditions of the work and teaching environment, and the opinions of workers and students, which allowed us to understand whether these alternatives will have a strong presence or not in the post-pandemic era.

With this investigation, it is possible to conclude the following:

First Question: Regarding appreciating telework/distance learning, there is no association for age, but there is for gender and parenthood. There is a strong association between parenthood and preference by distance model, but not for age or for gender. No association was found for desire for the future implementation of the alternatives.

Second Question: An association was found between respondents having their own workspace and appreciation for the distance model; in addition, an association was seen between internet quality and the latter. There was also an association between respondents having their own workspace and preferring the distance model.

Third question: As previously stated, people who responded to the survey, in general, were not willing to adopt telework/distance education.

The conclusions of this work could be different in the case of changes in legislation in Portugal or even the possibility for companies to comply with what is stipulated as voluntary telework. It should also be pointed out that, as the number of respondents is reduced, the conclusions cannot be seen in an absolute way. It should be noted that the survey was carried out at a time when the Portuguese had been confined for a year (with minor interruptions). There are several studies that point out various problems, such as those regarding mental health, the economy, and family, which may be the answer as to why the people who responded to this survey were eager to return to pre-pandemic life. This might be why respondents replied that they are not willing to adopt the teleworking and distance learning version, showing that they did not appreciate the compulsive experience of the emergency remote work (and learning) model. The only significant result is related to parenting, with those who have children preferring to work and study at a distance, with flexibility and at home. This is a conclusion that should be considered by lawmakers and companies in order to find models that are advantageous for both parties.

It would be interesting to repeat this questionnaire at a future time, in a world after confinement, where people are less eager to return to the life they had before this terrible pandemic.

Author Contributions: Conceptualization, A.D.M. and S.R.S.; methodology, A.D.M. and S.R.S.; software, A.D.M. and S.R.S.; validation, A.D.M. and S.R.S.; formal analysis, A.D.M. and S.R.S.; investigation, A.D.M. and S.R.S.; resources, A.D.M.; data curation, A.D.M. writing-original draft preparation, A.D.M. and S.R.S.; writing—review and editing, A.D.M. and S.R.S.; visualization, A.D.M. and S.R.S.; supervision, S.R.S.; project administration, S.R.S., funding acquisition, S.R.S. All authors have read and agreed to the published version of the manuscript. 
Funding: This research was funded through the following entities and grants: FCT (Fundação para a ciência e Tecnologia), a Portuguese national funding agency.

Institutional Review Board Statement: Not applicable.

Informed Consent Statement: Informed consent was obtained from all subjects involved in the study. Data Availability Statement: The data presented in this study are available on request from the corresponding author.

Conflicts of Interest: The authors declare no conflict of interest. 


\section{Appendix A}

Table A1. Level of appreciation, distance vs. face-to-face, and desire for future implementation vs. gender, age, parenthood, own equipment, internet quality, own workplace.

\begin{tabular}{|c|c|c|c|c|c|c|c|c|c|c|c|c|c|c|c|c|c|c|c|c|}
\hline \multirow[b]{2}{*}{ Gender } & \multicolumn{6}{|c|}{ Level of Appreciation } & \multicolumn{8}{|c|}{ Distance vs. Face-to-Face } & \multicolumn{6}{|c|}{ Desire for Future Implementation } \\
\hline & 1 & 2 & 3 & 4 & 5 & $X$ & Gender & 1 & 2 & 3 & 4 & 5 & $X$ & Gender & 1 & 2 & 3 & 4 & 5 & $X$ \\
\hline Female & $5.88 \%$ & $23.53 \%$ & $44.12 \%$ & $25.00 \%$ & $1.47 \%$ & 2.93 & Woman & $7.35 \%$ & $36.76 \%$ & $23.53 \%$ & $22.06 \%$ & $10.29 \%$ & 2.91 & Woman & $36.76 \%$ & $16.18 \%$ & $19.12 \%$ & $23.53 \%$ & $4.41 \%$ & 2.43 \\
\hline Male & $33.33 \%$ & $9.52 \%$ & $33.33 \%$ & $23.81 \%$ & $0.00 \%$ & 2.48 & Male & $9.52 \%$ & $33.33 \%$ & $19.05 \%$ & $28.57 \%$ & $9.52 \%$ & 2.95 & Male & $42.86 \%$ & $9.52 \%$ & $33.33 \%$ & $14.29 \%$ & $0.00 \%$ & 2.19 \\
\hline Total & $12.36 \%$ & $20.22 \%$ & $41.57 \%$ & $24.72 \%$ & $1.12 \%$ & 2.82 & Total & $7.87 \%$ & $35.96 \%$ & $22.47 \%$ & $23.60 \%$ & $10.11 \%$ & 2.82 & Total & $38.20 \%$ & $14.61 \%$ & $22.47 \%$ & $21.35 \%$ & $3.37 \%$ & 2.37 \\
\hline Age & 1 & 2 & 3 & 4 & 5 & $\mathrm{X}$ & Age & 1 & 2 & 3 & 4 & 5 & $\mathrm{X}$ & Age & 1 & 2 & 3 & 4 & 5 & $\mathrm{X}$ \\
\hline $18-25$ & $15.25 \%$ & $20.34 \%$ & $42.37 \%$ & $20.34 \%$ & $1.69 \%$ & 2.73 & $18-25$ & $10.17 \%$ & $49.15 \%$ & $16.95 \%$ & $18.64 \%$ & $5.08 \%$ & 2.59 & $18-25$ & $40.68 \%$ & $11.86 \%$ & $20.34 \%$ & $23.73 \%$ & $3.39 \%$ & 2.37 \\
\hline $26-35$ & $25.00 \%$ & $25.00 \%$ & $12.50 \%$ & $37.50 \%$ & $0.00 \%$ & 2.63 & $26-35$ & $12.50 \%$ & $12.50 \%$ & $25.00 \%$ & $25.00 \%$ & $25.00 \%$ & 3.38 & $26-35$ & $50.00 \%$ & $25.00 \%$ & $0.00 \%$ & $12.50 \%$ & $12.50 \%$ & 2.13 \\
\hline $36-45$ & $0.00 \%$ & $10.00 \%$ & $50.00 \%$ & $40.00 \%$ & $0.00 \%$ & 3.30 & $36-45$ & $0.00 \%$ & $10.00 \%$ & $20.00 \%$ & $40.00 \%$ & $30.00 \%$ & 3.90 & $36-45$ & $30.00 \%$ & $20.00 \%$ & $40.00 \%$ & $10.00 \%$ & $0.00 \%$ & 2.3 \\
\hline $46+$ & $0.00 \%$ & $25.00 \%$ & $50.00 \%$ & $25.00 \%$ & $0.00 \%$ & 3.00 & $46+$ & $0.00 \%$ & $8.33 \%$ & $50.00 \%$ & $33.33 \%$ & $8.33 \%$ & 3.42 & $46+$ & $25.00 \%$ & $16.67 \%$ & $33.33 \%$ & $25.00 \%$ & $0.00 \%$ & 2.58 \\
\hline Parenthood & 1 & 2 & 3 & 4 & 5 & $X$ & Parenthood & 1 & 2 & 3 & 4 & 5 & $x$ & Parenthood & 1 & 2 & 3 & 4 & 5 & $X$ \\
\hline No & $16.42 \%$ & $20.90 \%$ & $38.81 \%$ & $22.39 \%$ & $1.49 \%$ & 2.72 & No & $10.45 \%$ & $44.78 \%$ & $17.91 \%$ & $19.40 \%$ & $7.46 \%$ & 2.69 & No & $41.79 \%$ & $13.43 \%$ & $17.91 \%$ & $22.39 \%$ & $4.48 \%$ & 2.34 \\
\hline Yes & $0.00 \%$ & $18.18 \%$ & $50.00 \%$ & $31.82 \%$ & $0.00 \%$ & 3.14 & Yes & $0.00 \%$ & $9.09 \%$ & $36.36 \%$ & $36.36 \%$ & $18.18 \%$ & 3.64 & Yes & $27.27 \%$ & $18.18 \%$ & $36.36 \%$ & $18.18 \%$ & $0.00 \%$ & 2.45 \\
\hline Total & $12.36 \%$ & $20.22 \%$ & $41.57 \%$ & $24.72 \%$ & $1.12 \%$ & 2.82 & Total & $7.87 \%$ & $35.96 \%$ & $22.47 \%$ & $23.60 \%$ & $10.11 \%$ & 2.92 & Total & $38.20 \%$ & $14.61 \%$ & $22.47 \%$ & $21.35 \%$ & $3.37 \%$ & 2.37 \\
\hline Equipment & 1 & 2 & 3 & 4 & 5 & $X$ & Equipment & 1 & 2 & 3 & 4 & 5 & $X$ & Equipment & 1 & 2 & 3 & 4 & 5 & $X$ \\
\hline No & $33.33 \%$ & $33.33 \%$ & $33.33 \%$ & $0.00 \%$ & $0.00 \%$ & 2.00 & No & $0.00 \%$ & $66.67 \%$ & $33.33 \%$ & $0.00 \%$ & $0.00 \%$ & 2.33 & No & $100.00 \%$ & $0.00 \%$ & $0.00 \%$ & $0.00 \%$ & $0.00 \%$ & 1.00 \\
\hline Yes & $11.63 \%$ & $19.77 \%$ & $41.86 \%$ & $25.58 \%$ & $1.16 \%$ & 2.85 & Yes & $8.14 \%$ & $34.88 \%$ & $22.09 \%$ & $24.42 \%$ & $10.47 \%$ & 2.94 & Yes & $36.05 \%$ & $15.12 \%$ & $23.26 \%$ & $22.09 \%$ & $3.49 \%$ & 2.42 \\
\hline Total & $12.36 \%$ & $20.22 \%$ & $41.57 \%$ & $24.72 \%$ & $1.12 \%$ & 2.82 & Total & $7.87 \%$ & $35.96 \%$ & $22.47 \%$ & $23.60 \%$ & $10.11 \%$ & 2.92 & Total & $38.20 \%$ & $14.61 \%$ & $22.47 \%$ & $21.35 \%$ & $3.37 \%$ & 2.37 \\
\hline Internet & 1 & 2 & 3 & 4 & 5 & $X$ & Internet & 1 & 2 & 3 & 4 & 5 & $x$ & Internet & 1 & 2 & 3 & 4 & 5 & $x$ \\
\hline 3 & $13.33 \%$ & $26.67 \%$ & $40.00 \%$ & $20.00 \%$ & $0.00 \%$ & 2.67 & 3 & $6.67 \%$ & $26.67 \%$ & $20.00 \%$ & $40.00 \%$ & $6.67 \%$ & 3.13 & 3 & $33.33 \%$ & $13.33 \%$ & $33.33 \%$ & $20.00 \%$ & $0.00 \%$ & 2.40 \\
\hline 4 & $6.67 \%$ & $26.67 \%$ & $44.44 \%$ & $20.00 \%$ & $2.22 \%$ & 2.84 & 4 & $11.11 \%$ & $42.22 \%$ & $22.22 \%$ & $15.56 \%$ & $8.89 \%$ & 2.69 & 4 & $37.78 \%$ & $13.33 \%$ & $20.00 \%$ & $24.44 \%$ & $4.44 \%$ & 2.44 \\
\hline 5 & $15.38 \%$ & $7.69 \%$ & $38.46 \%$ & $38.46 \%$ & $0.00 \%$ & 3.00 & 5 & $0.00 \%$ & $30.77 \%$ & $26.92 \%$ & $30.77 \%$ & $11.54 \%$ & 3.23 & 5 & $34.62 \%$ & $19.23 \%$ & $23.08 \%$ & $19.23 \%$ & $3.85 \%$ & 2.38 \\
\hline Total & $12.36 \%$ & $20.22 \%$ & $41.57 \%$ & $24.72 \%$ & $1.12 \%$ & 2.82 & Total & $7.87 \%$ & $35.96 \%$ & $22.47 \%$ & $23.60 \%$ & $10.11 \%$ & 2.92 & Total & $38.20 \%$ & $14.61 \%$ & $22.47 \%$ & $21.35 \%$ & $3.37 \%$ & 2.37 \\
\hline Workplace & 1 & 2 & 3 & 4 & 5 & $X$ & Workplace & 1 & 2 & 3 & 4 & 5 & $x$ & Workplace & 1 & 2 & 3 & 4 & 5 & $X$ \\
\hline No & $15.38 \%$ & $15.38 \%$ & $46.15 \%$ & $23.08 \%$ & $0.00 \%$ & 2.77 & No & $15.38 \%$ & $7.69 \%$ & $23.08 \%$ & $38.46 \%$ & $15.38 \%$ & 3.31 & No & $53.85 \%$ & $0.00 \%$ & $30.77 \%$ & $15.38 \%$ & $0.00 \%$ & 2.08 \\
\hline Yes, sometimes & $14.29 \%$ & $0.00 \%$ & $42.86 \%$ & $28.57 \%$ & $14.29 \%$ & 3.29 & Yes, sometimes & $14.29 \%$ & $14.29 \%$ & $42.86 \%$ & $0.00 \%$ & $28.57 \%$ & 3.14 & Yes, sometimes & $14.29 \%$ & $14.29 \%$ & $14.29 \%$ & $42.86 \%$ & $14.29 \%$ & 3.29 \\
\hline Yes, always & $11.59 \%$ & $23.19 \%$ & $40.58 \%$ & $24.64 \%$ & $0.00 \%$ & 2.78 & Yes, always & $5.80 \%$ & $43.48 \%$ & $20.29 \%$ & $23.19 \%$ & $7.25 \%$ & 2.83 & Yes, always & $37.68 \%$ & $17.39 \%$ & $21.74 \%$ & $20.29 \%$ & $2.90 \%$ & 2.33 \\
\hline Total & $12.36 \%$ & $20.22 \%$ & $41.57 \%$ & $24.72 \%$ & $1.12 \%$ & 2.82 & Total & $7.87 \%$ & $35.96 \%$ & $22.47 \%$ & $23.60 \%$ & $10.11 \%$ & 2.92 & Total & $38.20 \%$ & $14.61 \%$ & $22.47 \%$ & $21.35 \%$ & $3.37 \%$ & 2.37 \\
\hline
\end{tabular}




\section{References}

1. World Health Organization. WHO Director-General's Opening Remarks at the Media Briefing on COVID-19-11 March 2020; World Health Organization: Geneva, Switzerland, 2020.

2. Belzunegui-Eraso, A.; Erro-Garcés, A. Teleworking in the Context of the Covid-19 Crisis. Sustainability 2020, 12, 3662. [CrossRef]

3. Carillo, K.; Cachat-Rosset, G.; Marsan, J.; Saba, T.; Klarsfeld, A. Adjusting to epidemic-induced telework: Empirical insights from teleworkers in France. Eur. J. Inf. Syst. 2021, 30. [CrossRef]

4. Hatabu, A.; Mao, X.; Zhou, Y.; Kawashita, N.; Wen, Z.; Ueda, M.; Takagi, T.; Tian, Y.-S. Knowledge, attitudes, and practices toward COVID-19 among university students in Japan and associated factors: An online cross-sectional survey. PLoS ONE 2020, 15, e0244350. [CrossRef] [PubMed]

5. Moorhouse, B. Adaptations to a face-to-face initial teacher education course 'forced' online due to the COVID-19 pandemic. J. Educ. Teach. 2020. [CrossRef]

6. Diário da República. Decreto do Presidente da República 14-A/2020; Diário da República: Lisbon, Portugal, 2020.

7. Presidência do Conselho de Ministros. Decreto-Lei 10-A/2020. In Diário da República 52/2020, 1 Suplemento, Série I de 2020-03-13; Presidência do Conselho de Ministros: Lisbon, Portugal, 2020.

8. Presidência do Conselho de Ministros. Decreto 2-A/2020. In Diário da República 57/2020, 1 Suplemento, Série I de 2020-03-20; Diário da República: Lisbon, Portugal, 2020.

9. Presidencia da Republica. Decreto do Presidente da República 6-A/2021; Presidencia da Republica: Brasília, Brazil, 2021.

10. Sobral, S.R. Ensino Superior: A Distância que Aproxima; DICT: Porto, Portugal, 2009.

11. Eurostat. Employed Persons Working from Home as a Percentage of the Total Employment, by Sex, Age and Professional Status (\%); European Statistical Office: Luxembourg, 2019.

12. PORDATA. Private Households with a Computer, with Internet Access and with Broadband Internet Access (\%); PORDATA: Geneva, Switzerland, 2021.

13. DRE. De teletrabalho, Noção. Artigo 165. In Código do Trabalho; Diário da República Eletrónico-DRE: Lisboa, Portugal, 2009.

14. Castelli, L.; Di Tella, M.; Benfante, A.; Romeo, A. The Spread of COVID-19 in the Italian Population: Anxiety, Depression, and Post-Traumatic Stress Symptoms. Can. J. Psychiatry 2020, 65, 731-732. [CrossRef]

15. Gutiérrez-Hernández, M.; Fanjul, L.; Díaz-Megolla, A.; Reyes-Hurtado, P.; Herrera-Rodríguez, J.; Enjuto-Castellanos, M.; Peñate, W. COVID-19 Lockdown and Mental Health in a Sample Population in Spain: The Role of Self-Compassion. Int. J. Environ. Res. Public Health 2021, 18, 2103. [CrossRef] [PubMed]

16. Rodríguez-Fernández, P.; González-Santos, J.; Santamaría-Peláez, M.; Soto-Cámara, R.; Sánchez-González, E.; González-Bernal, J. Psychological Effects of Home Confinement and Social Distancing Derived from COVID-19 in the General Population-A Systematic Review. Int. J. Environ. Res. Public Health 2021, 18, 8528. [CrossRef]

17. Nguyen, H.; Nguyen, M.; Do, B.; Tran, C.; Nguyen, T.; Pham, K.; Pham, L.; Tran, K.; Duong, T.; Tran, T.; et al. People with Suspected COVID-19 Symptoms Were More Likely Depressed and Had Lower Health-Related Quality of Life: The Potential Benefit of Health Literacy. J. Clin. Med. 2020, 9, 965. [CrossRef] [PubMed]

18. Shevlin, M.; McBride, O.; Murphy, J.; Miller, J.; Hartman, T.; Levita, L.; Bentall, R. Anxiety, depression, traumatic stress and COVID-19-related anxiety in the UK general population during the COVID-19 pandemic. BJPsych Open 2020, 6, E125. [CrossRef] [PubMed]

19. Mazza, C.; Ricci, E.; Biondi, S.; Colasanti, M.; Ferracuti, S.; Napoli, C.; Roma, P.A. Nationwide Survey of Psychological Distress among Italian People during the COVID-19 Pandemic: Immediate Psychological Responses and Associated Factors. Int. J. Environ. Res. Public Health 2020, 17, 3165. [CrossRef]

20. Justo-Alonso, A.; García-Dantas, A.; González-Vázquez, A.; Sánchez-Martín, M.; DelRío-Casanova, L. How did Different Generations Cope with the COVID-19 Pandemic? Early Stages of the Pandemic in Spain. Psicothema 2020, 32, 490-500. [PubMed]

21. Volken, T.; Zysset, A.; Amendola, S.; Klein Swormink, A.; Huber, M.; von Wyl, A.; Dratva, J. Depressive Symptoms in Swiss University Students during the COVID-19 Pandemic and Their Correlates. Int. J. Environ. Res. Public Health 2021, $18,1458$. [CrossRef] [PubMed]

22. Odriozola-González, P.; Planchuelo-Gómez, A.; Irurtia, M.; Luis-García, R. Psychological effects of the COVID-19 outbreak and lockdown among students and workers of a Spanish university. Psychiatry Res. 2020, 290, 113108. [CrossRef]

23. Wang, X.; Hegde, S.; Son, C.; Keller, B.; Smith, A.; Sasangohar, F. Investigating Mental Health of US College Students during the COVID-19 Pandemic: Cross-Sectional Survey Study. J. Med. Internet Res. 2020, 22, e22817. [CrossRef]

24. Sato, K.; Kobayashi, S.; Yamaguchi, M.; Sakata, R.; Sasaki, Y.; Murayama, C.; Kondo, N. Working from home and dietary changes during the COVID-19 pandemic: A longitudinal study of health app (CALO mama) users. Apetite 2021, 165. [CrossRef]

25. Tønnessen, Ø.; Dhir, A.; Flåten, B.-T. Digital knowledge sharing and creative performance: Work from home during the COVID-19 pandemic. Technol. Forecast. Soc. Chang. 2021, 170. [CrossRef]

26. Langvik, E.; Karlsen, H.; Saksvik-Lehouillier, I.; Sørengaard, T. Police employees working from home during COVID-19 lockdown: Those with higher score on extraversion miss their colleagues more and are more likely to socialize with colleagues outside work. Personal. Individ. Differ. 2021, 179. [CrossRef] 
27. Yoshimoto, T.; Fujii, T.; Oka, H.; Kawamata, K.; Matsudaira, K. Pain status and its association with physical activity, psychological stress, and telework among japanese workers with pain during the covid-19 pandemic. Int. J. Environ. Res. Public Health 2021, 18, 5595. [CrossRef]

28. Pirzadeh, P.; Lingard, H. Working from Home during the COVID-19 Pandemic: Health and Well-Being of Project-Based Construction Workers. J. Constr. Eng. Manag. 2021, 147. [CrossRef]

29. Pathak, D.; Bharathi, V.; Mala, P. The work-life balancing act: A study on the mandatory work from home due to COVID-19 on the IT and non-IT industry sectors. Int. J. Hum. Cap. Inf. Technol. Prof. 2021, 12, 1-20.

30. Ramos, V.; Ramos-Galarza, C.; Tejera, E. Teleworking in times of COVID-19. Rev. Interam. Psicol. Interam. J. Psychol. $2020,3,54$.

31. Raišienè, A.; Rapuano, V.; Varkulevičiūtè, K.; Stachová, K. Working from Home-Who Is Happy? A Survey of Lithuania's Employees during the COVID-19 Quarantine Period. Sustainability 2020, 12, 5332. [CrossRef]

32. Lemos, A.; Barbosa, A.; Monzato, P. Women in home office during a Covid-19 pandemic and the workfamily conflict configurations. J. Bus. Manag. 2020, 60. [CrossRef]

33. Weitzer, J.; Papantoniou, K.; Seidel, S. Working from home, quality of life, and perceived productivity during the first 50-day COVID-19 mitigation measures in Austria: A cross-sectional study. Int. Arch. Occup. Environ. Health 2021. [CrossRef]

34. Nguyen, M. Factors influencing home-based telework in Hanoi (Vietnam) during and after the COVID-19 era. Transportation 2021. [CrossRef] [PubMed]

35. Uehara, M.; Fujii, M.; Kobayashi, K. A Model of Stress Change under the First COVID-19 Pandemic among the General Public in Japanese Major Cities and Rural Areas. Sustainability 2021, 13, 1207. [CrossRef]

36. Hoffman, C. The Experience of Teleworking with Dogs and Cats in the United States during COVID-19. Animals 2021, 11, 268. [CrossRef]

37. Tokarchuk, O.; Gabriele, R.; Neglia, G. Teleworking during the Covid-19 Crisis in Italy: Evidence and Tentative Interpretations. Sustainability 2021, 13, 2147. [CrossRef]

38. Matisāne, L.; Paegle, L.; Eglīte, M.; Akūlova, L.; Linde, A.; Vanadziňš, I.; Mietule, I.; Lonska, J.; Litavniece, L.; Arbidāne, I.; et al. Reasons for Low Protection of Vulnerable Workers from COVID-19-Results from the Quantitative and Qualitative Study on Working Life in Latvia. Int. J. Environ. Res. Public Health 2021, 18, 5188. [CrossRef]

39. Labrague, L.J.; de Los Santos, J.A.A. Fear of COVID-19, psychological distress, work satisfaction and turnover intention among frontline nurses. J. Nurs. Manag. 2021, 29, 395-403. [CrossRef] [PubMed]

40. Mo, Y.; Deng, L.; Zhang, L.; Lang, Q.; Liao, C.; Wang, N.; Qin, M.; Huang, H. Work stress among Chinese nurses to support Wuhan in fighting against COVID-19 epidemic. J. Nurs. Manag. 2020, 28, 1002-1009. [CrossRef]

41. Tang, J. Understanding the Telework Experience of People with Disabilities. In ACM on Human-Computer Interaction; ACM: New York, NY, USA, 2021.

42. Fonner, K.L.; Roloff, M.E. Why Teleworkers are More Satisfied with Their Jobs than are Office-Based Workers: When Less Contact is Beneficial. J. Appl. Commun. Res. 2010, 38, 336-361. [CrossRef]

43. Morganson, V.; Major, D.; Oborn, K.; Verive, J.; Heelan, M. Comparing telework locations and traditional work arrangements: Differences in work-life balance support, job satisfaction, and inclusion. J. Manag. Psychol. 2010, 25. [CrossRef]

44. Allen, T.D.; Golden, T.D.; Shockley, K.M. How Effective Is Telecommuting? Assessing the Status of Our Scientific Findings. Psychol. Sci. Public Interest 2015, 16. [CrossRef] [PubMed]

45. Carelli, R.; Silva, J.; Domingues, C. Lawyers in Telework: A Study on the Impact of the COVID-19 Pandemic on Lawyers Work in the State of Rio De Janeiro. Labor Hum. Dev. Law J. 2021, 4. [CrossRef]

46. Johns Hopkins Coronavirus Resource Center. Johns Hopkins Coronavirus Resource Center-COVID; Johns Hopkins Coronavirus Resource Center: Baltimore, MD, USA, 2021.

47. WorldOMeters. WorldOMeters; WorldOMeters: Geneva, Switzerland, 2021. 